\title{
Response to ACTH in the newborn
}

\author{
S THOMAS, J F MURPHY, J DYAS, M RYALLS, AND I A HUGHES \\ Department of Child Health and Tenovus Institute, University of Wales College of Medicine, Cardiff
}

SUMmARY Adrenocortical function was studied in 52 newborn infants who had been divided into three groups: preterm well, preterm ill; and term ill. Basal plasma 17-hydroxyprogesterone concentrations were significantly increased in both groups of preterm infants. There was no significant difference in basal plasma cortisol concentrations, although they were highest in preterm ill infants. All infants responded to adrenocorticotrophic hormone (ACTH) stimulation $(36 \mu \mathrm{g} / \mathrm{kg}$ intramuscularly) with a two to threefold increase in the concentration of both steroids. The peak plasma 17-hydroxyprogesterone response was significantly higher in preterm ill infants. A subgroup of five infants, who were highly stressed but had undetectable basal plasma cortisol concentrations, also showed an appropriate response to ACTH. The results provide useful reference data to assess adrenal function in the infant of a mother given glucocorticoids during pregnancy. There is also a change from the pattern of fetal adrenal steroidogenesis soon after birth, which may be affected by exogenous ACTH stimulation. Roughly $10 \%$ of stressed newborns failed to synthesise cortisol basally; temporary glucocorticoid replacement for such infants may be appropriate.

Plasma concentrations of 17-hydroxyprogesterone are markedly raised in untreated infants with congenital adrenal hyperplasia due to 21-hydroxylase deficiency. ${ }^{1-3}$ In a recent study, concentrations of this steroid were also shown to be appreciably higher in stressed, ill newborn infants compared with healthy term infants. ${ }^{4}$ In some ill preterm infants plasma concentrations of 17-hydroxyprogesterone were as high as $100 \mathrm{nmol} / \mathrm{l}(30 \cdot 1$ $\mathrm{ng} / \mathrm{ml}$ ). Concomitant measurement of plasma cortisol concentrations, however, showed no correlation with the plasma 17-hydroxyprogesterone values. In about $10 \%$ of ill infants cortisol concentrations were undetectable $(<28 \mathrm{nmol} / \mathrm{l}(<1 \mu \mathrm{g} / 100 \mathrm{ml}))$.

Previous studies of adrenal function in newborn infants report variable plasma cortisol concentrations during the first week of life in infants. ${ }^{5-9}$ In general, basal plasma concentrations of cortisol exceed $100 \mathrm{nmol} / \mathrm{l}(3.6 \mu \mathrm{g} / 100 \mathrm{ml})$. Less information is available on cortisol values in preterm infants, particularly those who are stressed. ${ }^{10}$ This paper reports a systematic study of adrenocortical function in both preterm and term stressed infants. The plasma 17-hydroxyprogesterone and cortisol response to short term exogenous adrenocorticotrophic hormone (ACTH) stimulation is also reported. The results provide useful reference data to assess neonatal adrenal function after administration of glucocorticoid during gestation.

\section{Patients and methods}

Fifty two infants born in the maternity department of the University Hospital of Wales were studied. They were classified into three groups: preterm ill, preterm well, and term ill. The clinical assessment of seriously ill infants was the criterion used to identify those who were stressed. These infants had a variety of conditions, including respiratory problems requiring ventilation, perinatal asphyxia, septicaemia, and major neonatal surgery. Gestational age was assessed by the method of Ballard et al. ${ }^{11}$ The plasma 17-hydroxyprogesterone and cortisol response to ACTH stimulation was performed either on the third or fourth day after birth. Capillary blood samples were collected before and one hour after an intramuscular injection of Synacthen (Ciba). The dose used was $36 \mu \mathrm{g} / \mathrm{kg}$ body weight in a volume ranging from $0 \cdot 2-0.5 \mathrm{ml}$. Informed parental consent was obtained in each case and the study was approved by the hospital ethics committee.

Plasma concentrations of 17-hydroxyprogesterone ${ }^{12}$ and cortisol $^{13}$ were determined by radioimmunoassays using a ${ }^{125}$ I-radioligand and antisera coupled to solid phase supports. The volume of plasma required to perform both assays in duplicate was 140 $\mu \mathrm{l}$. Significant cross reactivity of the cortisol antiserum was observed for 21-deoxycortisol $(65 \%)$ and prednisolone $(6 \cdot 9 \%)$. For the 17-hydroxyprogester- 
one antiserum the cross reactivity with progesterone and 17 -hydroxypregnenolone was $5.9 \%$ and $7.4 \%$, respectively.

Statistical analyses of the 17-hydroxyprogesterone and cortisol data were performed using log transformation and the $F$ test.

When comparing values before and after administration of Synacthen analysis of covariance was used to adjust for the differences in the values before administration.

\section{Results}

Table 1 shows the clinical details of the 52 infants studied. As expected, preterm infants who were ill had lower birth weights and gestational ages. The values for the group were not significantly different. Table 2 and Figure 1 summarise basal and peak plasma cortisol and 17-hydroxyprogesterone responses to ACTH stimulation in each of the three groups of infants.

The mean basal plasma cortisol concentration was highest in the group of preterm ill infants, but the difference was not significant. Basal plasma 17hydroxyprogesterone concentrations were significantly higher in both groups of preterm infants $(p<0 \cdot 05)$. Term ill infants had 17-hydroxyprogesterone concentrations similar to their healthy counterparts. ${ }^{3}$ In a more recent study of 17 -hydroxyprogesterone concentrations determined in filter paper blood spots obtained from 100 healthy term

Table 1 Clinical details of infants studied

\begin{tabular}{llllll}
\hline Group ( $n=)$ & \multicolumn{2}{l}{ Birth weight $(g)$} & & \multicolumn{2}{l}{ Gestation (weeks) } \\
\cline { 2 - 3 } & Mean (SD) & Range & & Mean (SD) & Range \\
\hline Preterm well (15) & $1660(462)$ & $0 \cdot 87-2 \cdot 4$ & & $32 \cdot 8(2 \cdot 6)$ & $28-36$ \\
Preterm ill (26) & $1568(542)$ & $0 \cdot 82-2 \cdot 7$ & & $31 \cdot 4(2 \cdot 8)$ & $28-35$ \\
Term ill (11) & $3080(533)$ & $2 \cdot 57-4.49$ & & $38.9(1 \cdot 04)$ & $38-41$ \\
\hline
\end{tabular}

Table 2 Mean (SEM) plasma cortisol and 17-hydroxyprogesterone response to ACTH stimulation

\begin{tabular}{|c|c|c|c|c|}
\hline \multirow[t]{3}{*}{ Group } & \multicolumn{2}{|c|}{ Cortisol (nmol/l) } & \multirow{2}{*}{\multicolumn{2}{|c|}{$\begin{array}{l}\text { 17-hydroxyprogesterone } \\
\text { (nmolll) }\end{array}$}} \\
\hline & \multirow{2}{*}{ Basal } & \multirow{2}{*}{ Peak } & & \\
\hline & & & Basal & Peak \\
\hline Preterm well & $\begin{array}{l}306 \cdot 3 \\
(44 \cdot 5)\end{array}$ & $\begin{array}{l}631 \cdot 3 \\
(77 \cdot 5)\end{array}$ & $\begin{array}{l}12 \cdot 9 \\
(2 \cdot 68)\end{array}$ & $\begin{array}{l}23 \cdot 6 \\
(3 \cdot 45)\end{array}$ \\
\hline Preterm ill & $\begin{array}{l}536.9 \\
(93.9)\end{array}$ & $\begin{array}{l}996 \cdot 1 \\
(136 \cdot 3)\end{array}$ & $\begin{array}{l}14 \cdot 7 \\
(1 \cdot 75)\end{array}$ & $\begin{array}{l}32 \cdot 1 \\
(3 \cdot 5)\end{array}$ \\
\hline Term ill & $\begin{array}{l}372 \cdot 4 \\
(156 \cdot 7)\end{array}$ & $\begin{array}{l}646 \cdot 6 \\
(100 \cdot 5)\end{array}$ & $\begin{array}{l}7 \cdot 2 \\
(1 \cdot 5)\end{array}$ & $\begin{array}{l}14 \cdot 2 \\
(2 \cdot 9)\end{array}$ \\
\hline
\end{tabular}

Conversion: SI to traditional units-Cortisol: $1 \mathrm{nmol} / \mathrm{l} \approx 0.036 \mu \mathrm{g} / 100 \mathrm{ml}$. 17-hydroxyprogesterone: $1 \mathrm{nmol} / \mathrm{l} \approx 0.31 \mathrm{ng} / \mathrm{ml}$.

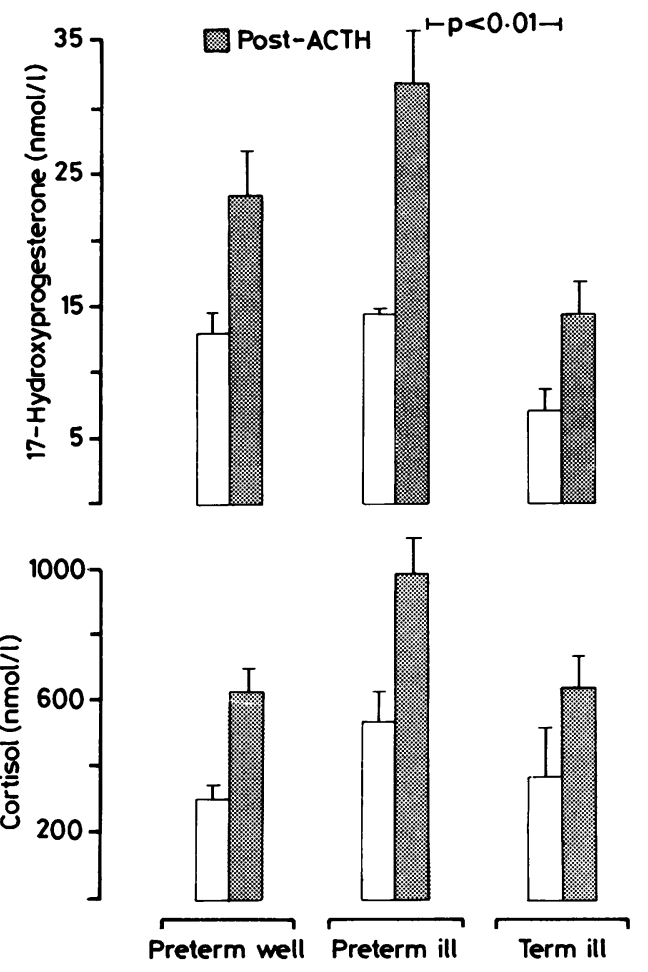

Fig. 1 Plasma concentrations of 17-hydroxyprogesterone (upper panel) and cortisol (lower panel) before and after ACTH stimulation in newborn infants. Values are mean (SEM).

Conversion: SI to traditional units-17-hydroxyprogesterone: $1 \mathrm{nmol} / \mathrm{l} \approx 0.31$ $\mathrm{ng} / \mathrm{ml}$. Cortisol: $1 \mathrm{nmol} / \mathrm{l} \approx 0.036 \mu \mathrm{g} / 100 \mathrm{ml}$.

infants, the mean (SD) concentration was $7.5(2 \cdot 3)$ $\mathrm{nmol} / \mathrm{l}(2 \cdot 3(0 \cdot 71) \mathrm{ng} / \mathrm{ml})$ (unpublished observations). All infants responded to ACTH stimulation with a two to threefold increase in both plasma cortisol and 17-hydroxyprogesterone concentrations. When the 음 results were adjusted for the differences in basal plasma concentrations, using analysis of covariance, there was no difference in the cortisol response $\bar{N}$ between the three groups of infants. In contrast, the 0 peak plasma 17-hydroxyprogesterone response in preterm ill infants was significantly higher than the response in term ill infants $(p<0 \cdot 01)$.

Basal plasma cortisol concentrations were undetectable $(<28 \mathrm{nmol} / \mathrm{l}(<1 \mu \mathrm{g} / 100 \mathrm{ml}))$ in five infants (9.6\% of the total). Table 3 summarises the clinical details of these infants and the individual plasma cortisol responses to ACTH stimulation. The plasma cortisol concentration increased into the normal range in each infant after acute ACTH stimulation. 
Table 3 Plasma cortisol response to ACTH stimulation with undetectable basal cortisol concentrations

\begin{tabular}{lllll}
\hline Clinical condition & $\begin{array}{l}\text { Birth weight } \\
(\mathrm{g})\end{array}$ & $\begin{array}{l}\text { Gestation } \\
\text { (weeks) }\end{array}$ & \multicolumn{2}{c}{\begin{tabular}{l} 
Cortisol \\
\cline { 3 - 5 } (nmolll)
\end{tabular}} \\
\hline $\begin{array}{l}\text { Hypoplastic left } \\
\text { heart syndrome }\end{array}$ & 2750 & 39 & $<28$ & 704 \\
$\begin{array}{l}\text { Birth asphyxia } \\
\text { Diaphragmatic hernia; } \\
\text { neonatal surgery }\end{array}$ & 3800 & 41 & $<28$ & 378 \\
$\begin{array}{l}\text { IRDS; ventilated } \\
\text { IRDS; intraventricular } \\
\text { haemorrhage }\end{array}$ & 2360 & 39 & $<28$ & 204 \\
\hline
\end{tabular}

Conversion: $S I$ to traditional units-Cortisol: $1 \mathrm{nmol} / \mathrm{l} \approx 0.036 \mu \mathrm{g} / 100 \mathrm{ml}$. IRDS=idiopathic respiratory distress syndrome.

\section{Discussion}

Simultaneous measurements of plasma cortisol and 17-hydroxyprogesterone concentrations in newborns before and after acute ACTH stimulation have not been reported previously. The use of sensitive and specific radioimmunoassays for both cortisol and 17-hydroxyprogesterone concentrations permitted measurement of these steroid concentrations in routine capillary heel prick samples collected from small infants.

Basal plasma cortisol and 17-hydroxyprogesterone concentrations were higher in preterm infants compared with term ill infants. In the case of 17-hydroxyprogesterone, concentrations in preterm ill infants were significantly higher. This confirms results obtained in a previous study ${ }^{4}$ and emphasises the need to determine normal values for plasma steroid concentrations in relation to gestational age. In pilot newborn screening programmes for congenital adrenal hyperplasia, ${ }^{14-16}$ there have been unacceptably high false positive rates from raised blood spot 17-hydroxyprogesterone concentrations in ill preterm infants with non-adrenal disorders.

It is standard practice to give a synthetic 1-24 amino acid residue of natural ACTH as a short term test of adrenal insufficiency. The usual dose, $250 \mu \mathrm{g}$ given either intramuscularly or intravenously, is probably far in excess of that required to produce maximum steroidogenesis in adults, ${ }^{17}$ let alone preterm infants. In a recent study of the 17hydroxyprogesterone and cortisol responses to different doses of exogenous ACTH compared with those obtained using insulin induced hypoglycaemia as a 'physiological' stimulus, it was shown that the appropriate ACTH dose infused over 10 minutes was $0 \cdot 2 \mu \mathrm{g} / \mathrm{kg} .{ }^{18}$ This produced a response indistinguishable from the plasma cortisol response to hypoglycaemia. For our study, a Synacthen dose related to body weight was chosen based on previous experience with ACTH stimulation tests in children. ${ }^{19}$ All three groups of infants responded with an appropriate increase in plasma cortisol and 17-hydroxyprogesterone concentrations. Previous studies, using plasma cortisol determinations only, have also shown substantial neonatal adrenocortical responses to ACTH even after prenatal administration of dexamethasone. ${ }^{510}$ This is the first reported study of the use of plasma 17-hydroxyprogesterone measurements as an index of ACTH responsiveness in newborn infants. The data for this age group complement the nomograms developed by New $e t$ $a l^{20}$ in older children relating basal and ACTH stimulated concentrations of 17-hydroxyprogesterone to distinguish different forms of 21-hydroxylase deficiency.

Roughly $10 \%$ of infants in this study had basal plasma cortisol concentrations that were undetectable. An early gestational age was not a factor, but all five infants were very ill. There was an adequate rise in cortisol concentrations after acute ACTH stimulation. The reason for this transient adrenal insufficiency is not clear. There is a pronounced change in the pattern of adrenal steroidogenesis during early adaptation to extrauterine life. ${ }^{21}$ The concentration of placental steroids such as progesterone and oestradiol are cleared rapidly from the neonatal circulation. This removes the inhibiting effect on adrenal 3ßol-hydroxysteroid dehydrogenase activity, which is essential for the synthesis of $\triangle^{4}$-3-hydroxysteroids such as cortisol and aldosterone. Fetal adrenal cells maintained in tissue culture secrete predominantly $\triangle^{5}-3 \beta$-hydroxysteroids, but are exquisitively sensitive to ACTH and change to a pattern of $\triangle^{4}-3$-hydroxysteroid secretion. ${ }^{22} 23$ Perhaps this switch in enzyme activity was mediated in vivo after exogenous ACTH stimulation in those infants with low basal plasma cortisol concentrations. ACTH also serves to induce a transcriptional increase in synthesis of new enzyme and hence maximal steroidogenesis. Thus, in part, the effect of exogenous ACTH may be mediated via 21-hydroxylation of 17-hydroxyprogesterone where there is partial deficiency of 21-hydroxylase activity. Figure 2 summarises diagrammatically a possible explanation for the response observed in vivo to acute ACTH stimulation in early extrauterine life. Pituitary ACTH secretion, which normally responds to stress at delivery even after prenatal treatment with dexamethasone ${ }^{24}{ }^{25}$ is possibly deficient due to decreased production of hypothalamic corticotrophin releasing factor. Now that synthetic corticotrophin releasing factor is available for clinical use, ${ }^{26}$ it may be possible to study hypothalamic-pituitaryadrenal function in stressed preterm and term infants in more detail.

Normal adrenal steroidogenesis is clearly essential 


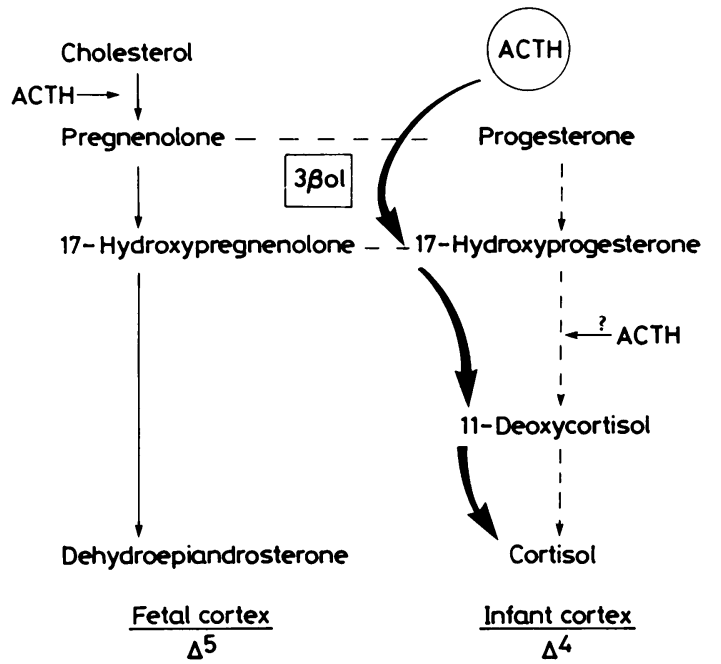

Fig. 2 An hypothesis for the effect of exogenous ACTH stimulation on adrenal steroidogenesis in the newborn. $3 \beta o l$ refers to the enzyme, $3 \beta$-hydroxysteroid dehydrogenase.

for survival after birth. With direct assays for cortisol using only $20 \mu \mathrm{l}$ plasma now available, ${ }^{13}$ it is possible to rapidly identify stressed infants whose basal cortisol concentrations may be abnormally low. Temporary administration of exogenous ACTH or glucocorticoid replacement may be beneficial in the management of such infants in early neonatal life.

We thank R G Newcombe for statistical analyses, and the technical staff of the Steroid SupraRegional Assay Laboratory. Tenovus Institute, for steroid measurements.

\section{References}

1 Barnes ND, Atherden SM. Diagnosis of congenital adrenal hyperplasia by measurement of plasma 17-hydroxyprogesterone. Arch Dis Child 1972;47:62-5.

2 Youssefnejadian E, David R. Early diagnosis of congenital adrenal hyperplasia by measurement of 17-hydroxyprogesterone. Clin Endocrinol 1975;4:451-4.

${ }^{3}$ Hughes IA, Riad-Fahmy D, Griffiths K. Plasma $170 \mathrm{H}-$ progesterone concentrations in newborn infants. Arch Dis Child 1979;54:347-9.

${ }^{4}$ Murphy JF, Joyce BG, Dyas J, Hughes IA. Plasma 17hydroxyprogesterone concentrations in ill newborn infants. Arch Dis Child 1983;58:532-4.

5 Gutai J, George R, Koeff S, Bacon GE. Adrenal response to physical stress and the effect of adrenocorticotrophic hormone in newborn infants. J Pediatr 1972:81:719-25.

6 Barnhart BJ, Carlson CV, Reynolds JW. Adrenal cortical function in the postmature fetus and newborn infant. Pediatr Res 1980;14:1367-9.

7 Vernes I, Dohanics J. Toth G. Pongrácz J. Maturation of the circadian rhythm of the adrenocortical functions in human neonates and infants. Horm Res 1980;12:237-44.

${ }^{8}$ Sippell WG, Dörr HG, Bidlingmaier F, Knorr D. Plasma levels of aldosterone, corticosterone, 11-deoxycorticosterone, progesterone, 17-hydroxyprogesterone. cortisol and cortisone during infancy and childhood. Pediatr Res 1980:14:39-46.

"Sippell WG. Bidlingmaicr F, Knorr D. Development of endogenous glucocorticoids, mineralocorticoids and progestins in the human fetal and perinatal period. Influence of antenatal treatment with betamethasone or phenobarbital. Eur J Clin Pharmacol 1980;18:95-104.

10 Ohrlander S. Gennser G. Nilsson KO. Encroth P. ACTH test to neonates after administration of corticosteroids during gestation. Obstet Gynecol 1977:49:691-4.

"Ballard J, Kazmaier K. Driver M. A simplified assessment of gestational age. Pediatr Res 1977:11:374.

12 Dyas J, Read GF, Guha-Maulik T, Hughes IA, Riad-Fahmy D. A rapid assay for $17 \alpha \mathrm{OH}$-progesterone in plasma, saliva and amniotic fluid using a magnetisable solid-phase antiserum. Ann Clin Biochem 1984:21:417-24.

13 Riad-Fahmy D, Read GF, Gaskell SJ, Dyas J, Hindawi R. A simple, direct radioimmunoassay for plasma cortisol, featuring a ${ }^{125}$ I-radioligand and a solid-phase separation technique. Clin Chem 1979:25:665-8.

${ }^{14}$ Pang S, Murphy W, Levine LS, et al. A pilot newborn screening for congenital adrenal hyperplasia in Alaska. J Clin Endocrinol Metab 1982:55:413-20.

15 Riordan FAI, Wood PJ. Wakelin K. Betts P. Clayton BE. Blood spot $17 \alpha$-hydroxyprogesterone radioimmunoassay for diagnosis of congenital adrenal hyperplasia and home monitoring of corticosteroid replacement therapy. Lancet 1984;i:708-11.

it Shimozawa K. Saisho S. Saito N, et al. A neonatal massscreening for congenital adrenal hyperplasia in Japan. Acta Endocrinol 1984;107:513-8.

${ }^{17}$ Kehlet H. Binder C. Value of an ACTH stimulation test in assessing the hypothalamic-pituitary-adrenal function in glucocorticoid-treated patients. $\mathrm{Br}$ Med J 1973;ii:147-9.

18 Graybeal ML, Fang VS. Physiological dosing of exogenous ACTH. Acta Endocrinol 1985;108:401-6.

19 Barnes ND. Joseph JM. Atherden SM. Clayton BM. Functional tests of adrenal axis in children with measurement of plasma cortisol by competitive protein binding. Arch Dis Child 1972:47:66-73.

20) New MI, Lorenzen F, Lerner AJ, et al. Genotyping steroid 21-hydroxylase deficiency: hormonal reference data. J Clin Endocrinol Metab 1983:57:320-6.

21 Winter JSD. The adrenal cortex in the fetus and neonate. In Anderson DC, Winter JSD, eds. Adrenal cortex. London Butterworths, 1985:32-56.

22 Fujieda K, Faiman C, Reyes FI, Winter JSD. The control of steroidogenesis in human fetal adrenal cells in tissue culture. $I$. Responses to adrenocorticotrophin. J Clin Endocrinol Metab 1981:53:34-8.

${ }^{23}$ Simorian MH, Gill GN. Regulation of the fetal human adrenal cortex: effects of adrenocorticotrophin on growth and function of monolayer cultures of fetal and definitive zone cells Endocrinology 1981:108:1769-79.

${ }^{24}$ Huhtaniemi I. Koivisto M. Pakarinen A. Tuimala R, Kauppila A. Pituitary-adrenal and testicular function in preterm infants after prenatal dexamethasone treatment. Acta Paediatr Scand 1982:71:425-9.

25 Pohjavuori M. Fyrhquist F. Vasopressin. ACTH and neonatal haemodynamics. Acta Paediatr Scand [Suppl] 1983;305:79-83.

26 Lytras N. Grossman A. Perry L, et al. Corticotrophin releasing factor: responses in normal subjects and patients with disorders of the hypothalamus and pituitary. Clin Endocrinol 1984;20: $71-84$.

Correspondence to Dr I A Hughes, Department of Child Health, University of Wales College of Medicine. Heath Park. Cardiff CF4 $4 \mathrm{XN}$.

Received 27 August 1985 